As ophthalmologists it is our obvious duty to press for a proper ophthalmic service for all classes of the community by qualified medical practitioners with ophthalmic training who should receive an adequate fee for their work. A revision and extension of the National Ophthalmic Treatment Board would seem to be the ideal solution of our part of the problem.

We view with alarm the prospect of state control of the voluntary hospitals and we think that free choice of doctor must be accorded to the patient for the success of any scheme of re-organization of the health services. And, lastly, a similar freedom should be meted out to the medical practitioner. May we not agree with that great Scottish physician who, in one of his prefaces, said he thought, with Adam Smith, that a mediciner should be as free to exercise his gifts as an architect or a mole catcher?

\title{
A Singular Error
}

Madame de Staël's well known epithet vulgaire, applied to the writings of Jane Austen, was a blow which staggered lovers of the Hampshire novelist's books until some one suggested that the adjective in this case meant "commonplace" rather than "low." Thence onwards everything was comfortable. Our own comfort is often disturbed round about the beginning of each month by the fear that we have missed some dreadful howler in reading the proofs: Could a graph of our feelings be constructed it would show a regular rise and fall each month over a good many years with occasional excrescences above the common level where we have blundered more than usual. We regret to have to record that this happened in our October number, where, on page 436, occur the words " There is little or no data." We understand that this slipshod construction is increasingly common in physical literature. That such a monstrous error should be prevalent is indeed a flaw in a centuries-long system of classical education. There is, however, no reason to despair, all will be well when the new Education Act is passed and we may look forward with confidence to the time when, in the words of our erudite Minister of Education, the boy well grounded in Latin will " take" (not only) "the internal combustion engine" (but also the whole range of physics) " in his stride." 